\title{
FATAL BRONCHOVASCULAR FISTULA AFTER A SINGLE LUNG TRANSPLANTATION: A CASE REPORT
}

\author{
doi: $10.1590 / \mathbf{S 1 8 0 7 - 5 9 3 2 2 0 0 9 0 0 1 0 0 0 0 1 5}$
}

Marcos Naoyuki Samano, ${ }^{\mathrm{I}}$ Juliana Akemi Saka, ${ }^{\mathrm{I}}$ Marlova Luzzi Caramori, ${ }^{\mathrm{II}}$ Paulo Manuel Pêgo-Fernandes, ${ }^{\mathrm{I}}$ Fabio Biscegli Jatene $^{\mathrm{I}}$

\section{INTRODUCTION}

Airway complications following bronchial anastomosis remain an important cause of morbidity and mortality in patients who undergo lung transplantation. ${ }^{1}$ The main complications associated with this procedure are airway stenosis, dehiscence and tissue granulation. ${ }^{2}$ Bronchovascular fistulas are a very rare but serious and fatal complication of altered bronchial anastomotic healing, which leads to massive hemoptysis and death in almost all cases. We report the first Brazilian case of fatal hemoptysis due to the formation of a bronchial fistula within the pulmonary artery during the early postoperative period of a left singlelung transplantation for idiopathic fibrosis.

\section{CASE DESCRIPTION}

A 59-year-old male underwent a left single-lung transplant for idiopathic pulmonary fibrosis after being on a waiting list for 4 months. The operation was uneventful, with a total ischemic time of 170 minutes. Bronchial anastomosis was performed using a telescoping technique and with a continuous suture using 4-0 Prolene (Ethicon, Somerville, $\mathrm{NJ}$ ) in the posterior membranous portion and invaginating "U" stitch sutures in the cartilaginous portion. The venous and arterial anastomoses were made with continuous sutures using 5-0 Prolene.

The patient was extubated after 12 hours of mechanical ventilation. The patient's ICU length-of-stay was 14

\footnotetext{
I Thoracic Surgery Division, Heart Institute (InCor), Hospital das Clínicas da Faculdade de Medicina da Universidade de São Paulo - São Paulo/SP, Brazil. II Pulmonology Division, Heart Institute (InCor), Hospital das Clínicas da Faculdade de Medicina da Universidade de São Paulo - São Paulo/SP, Brazil. Email: marcos.samano@incor.usp.br Tel.: 55 113069.5248
}

days, and the total length-of-stay was 28 days. Initial immunosuppressive therapy included tacrolimus, prednisone and azathioprine, substituted 14 days later with mycophenolate mofetil, due to leukopenia. Prophylaxis against Cytomegalovirus and $P$. carinii was provided by treatment with ganciclovir and co-trimoxazole. The patient developed significant inflammatory infiltration in the left lung on the $14^{\text {th }}$ postoperative day. Transbronchial biopsy showed minimal rejection (grade A1) of the transplanted lung, and the patient was treated with methylprednisolone resulting in total recovery. A bronchoscopic evaluation also showed partial necrosis at the anastomotic site, but no signs of dehiscence (Figure 1).

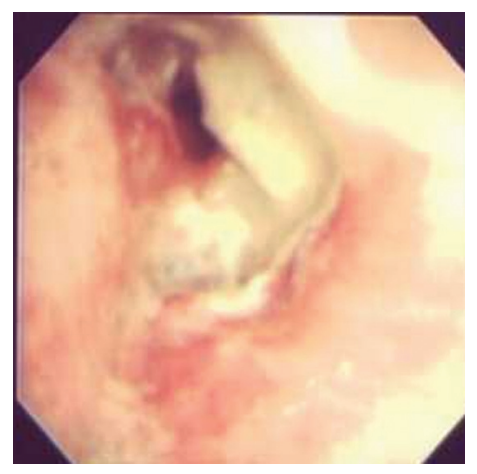

Figure 1 - Endoscopic image of necrosis in the bronchial anastomosis

Ten days after discharge, on the $38^{\text {th }}$ postoperative day, the patient had a massive hemoptysis and died of hypovolemic shock in the emergency room. An autopsy revealed a fistula between the pulmonary artery and the left main bronchus, which was identified as the cause of the massive hemoptysis (Figures 2 and 3).

Analysis of bronchoalveolar lavage (BAL) fluid obtained shortly after the surgical procedure indicated the presence of Serratia marcescens and Staphylococcus epidermidis. Ten 


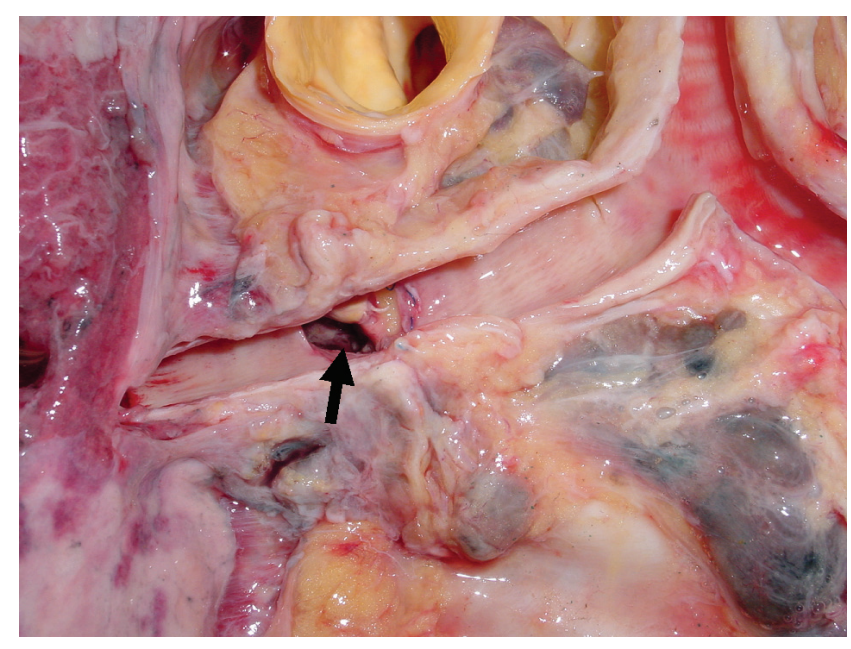

Figure 2 - Posterior view of the fistula orifice in the donor bronchus right below the anastomotic site

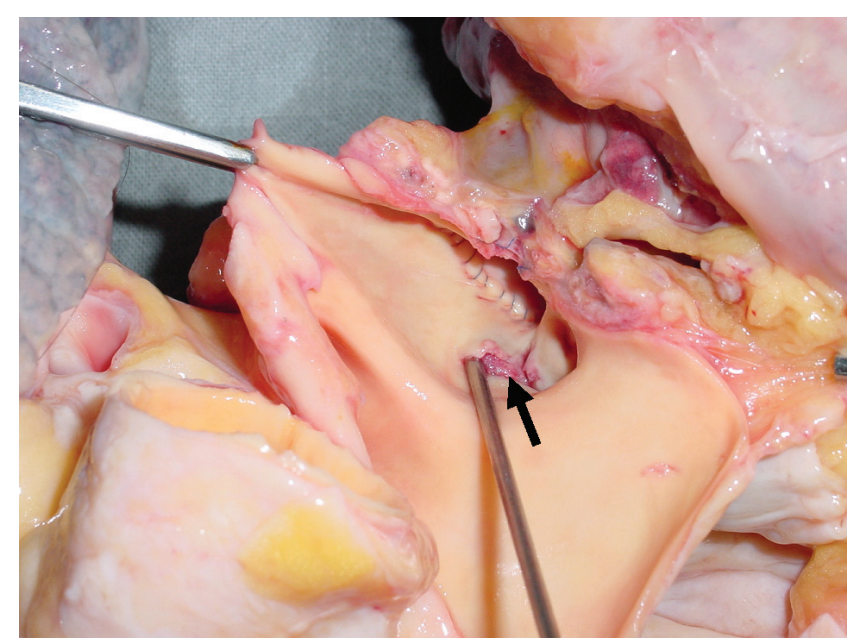

Figure 3 - Autopsy examination of the bronchovascular fistula orifice through the pulmonary artery

days later, analysis of sputum cultures revealed the presence of coagulase-positive Staphylococcus, Corynebacterium sp. and Pseudomonas aeruginosa. Antimicrobial therapy included second, third and fourth generation cephalosporins, amikacin, ciprofloxacin and imipenem. Although several tests for mycobacteria and fungi were performed from BAL and sputum samples, there was no evidence for the presence of such infections.

\section{DISCUSSION}

Fistulas between vascular structures and the tracheobronchial tree are a potentially fatal condition associated with hemoptysis. ${ }^{3,45}$ The majority of these types of complications are related to general thoracic surgical procedures, especially aneurysms of the thoracic aorta. ${ }^{6}$ The appearance of bronchovascular fistulas after lung transplantation has been previously reported, but mainly in association with the pulmonary artery. ${ }^{3,5,7}$ Knight et al. ${ }^{4}$ reported three cases of fatal bronchial fistulas occurring at the azygos vein and the descending aorta.

The treatment for this condition depends on early diagnosis and the correction of bronchial and vascular communication by restricting bleeding and avoiding hypovolemic shock. ${ }^{78}$ If only one lung is affected, selective intubation is indicated in order to preserve the other lung by avoiding "blood drainage" and allowing some ventilation.

Surgical treatment is based on pneumonectomy or resection of the fistulas with reconstruction of the pulmonary artery and bronchial anastomosis; however, the morbimortality of this emergency procedure is excessively high, and its recommendation depends on the risks, underlying conditions and expected complications. ${ }^{8}$ Davidson et al. ${ }^{9}$ reported a case of a pulmonary artery-tobronchial stump fistula after a right upper lobectomy that was successfully treated with endovascular placement of a covered stent. Management by endovascular stent placement has been primarily used for aortobronchial fistulas related to aneurysms or pseudoaneurysms of the descending thoracic aorta with successful occlusion..$^{10,11,12}$ Unfortunately, urgent treatment of our patient was not possible, and the patient died shortly after arriving in the emergency room.

Abnormal healing of the bronchus is the cornerstone for the occurrence of bronchial anastomotic complications, since deficient vascularization causes ischemia of the bronchial tree after anastomosis. Although bronchial artery anastomosis has been supported by some authors, it is technically complicated and ineffective. ${ }^{13}$ Other techniques, such as using a short donor-derived bronchial stump, reinforcement of the site of anastomosis with an omental flap, donor pericardium or intercostal muscle pedicle, and the use of a telescoping technique, have been shown to be more effective in promoting bronchial healing, improving the coverage of anastomosis and enhancing neovascularization. ${ }^{14,15}$ The telescoping technique for bronchial anastomosis was introduced in order to minimize the risk of complications. In addition, this technique is especially useful when there are discrepancies in bronchial size between the recipient and donor. ${ }^{16}$ This technique was used in the first reported cases of bronchial anastomosis, including in the case presented here; however, end-to-end anastomosis is more often performed contemporarily. End-to-end anastomosis has been shown to be superior to the telescoping technique with respect to the incidence of complications, such as severe stenosis, ischemia and dehiscence. ${ }^{17,18}$ However, there are no reports that consider the implications of end-to-end anastomosis on fistula formation.

Surveillance bronchoscopy allows for the direct evaluation of anastomosis healing and the appearance of related complications. When performed in conjunction with 
transbronchial biopsy and BAL, surveillance bronchoscopy can be a very important tool for patient follow-up after lung transplantation. This technique is also useful for the early diagnosis of infection by Aspergillus and for the identification of ulcerative and necrotizing defects of the airways. ${ }^{5}$ Unfortunately, in our patient, cultures of BAL and sputum specimens revealed no signs of fungal infection. Previous bronchoscopy revealed the presence of necrotic and granulated tissue around the site of anastomosis, but bronchoscopy was not able to identify the formation of a fistula. Fungal infection, or aspergillosis, is frequently associated with bronchial complications, such as stenosis, dehiscence and bronchovascular fistulas. ${ }^{4,5,7,19}$ This infection increases the risk of morbimortality after lung transplantation, which varies according to the time of onset, the site of infection and the type of transplant procedure. ${ }^{20}$

Bronchovascular fistulas are a very dangerous complication of airway anastomoses. The type or form of treatment depends on early diagnosis and is based on re-operation or stent placement. Even though it is a very rare condition, improved evaluation of the factors that contribute to fistula formation must be developed and always considered during follow-up evaluations of lung transplant patients. In addition, surveillance bronchoscopy should be routinely performed in order to identify patients at risk for developing fistulas.

\section{REFERENCES}

1. Kshettry VR, Kroshus TJ, Hertz MI, Hunter DW, Shumway SJ, Bolman III RM. Early and late airway complications after lung transplantation: incidence and management. Ann Thorac Surg. 1997;63:1576-83.

2. Murthy SC, Blackstone EH, Gildea TR, Gonzalez-Stawinski GV, Feng $\mathrm{J}$, Budev M, et al. Impact of anastomotic airway complications after lung transplantation. Ann Thorac Surg. 2007;84:401-9, 409.e1-4.

3. Kessler R, Massard G, Warter A, Wihlm JM, Weitzenblum E. Bronchialpulmonary artery fistula after unilateral lung transplantation: a case report. J Heart Lung Transplant. 1997;16:674-7.

4. Knight J, Elwing JM, Milstone A. Bronchovascular fistula formation: a rare airway complication after lung transplantation. J Heart Lung Transplant. 2008;27:1179-85.

5. Slatore CG, Yank V, Jewell KD, Fligner CL. Bronchial-pulmonary artery fistula with fatal massive hemoptysis caused by anastomotic bronchial aspergillus infection in a lung transplant recipient. Resp Care. 2007;52:1542-5.

6. Picichè M, De Paulis R, Fabbri A, Chiariello L. Postoperative aortic fistulas into the airways: etiology, pathogenesis, presentation, diagnosis, and management. Ann Thorac Surg. 2003;75:1998-2006.

7. Rea F, Marulli G, Loy M, Bortolotti L, Giacometti C, Schiavon M, et al. Salvage right pneumonectomy in a patient with bronchial-pulmonary artery fistula after bilateral sequential lung transplant. J Heart Lung Transplant. 2006;25:1383-6.

8. Kotzampassaki N, Corpataux JM, Pasche P, Magnusson L, Ris HB. Superficial femoral vein as substitute for pulmonary artery reconstruction after resection for bronchovascular fistula. J Thorac Cardiovasc Surg. 2008;136:525-7.

9. Davison BD, Ring DH, Bueno R, Jaklitsch MT. Endovascular stent-graft repair of a pulmonary artery-bronchial fistula. J Vasc Interv Radiol. 2003;14:929-32.

10. Abdul-Ghani A, Pisipati S, McWilliams R, Page RD. Aorto-bronchial fistula following aortic and bronchial stenting of a thoracic aneurysm. Eur J Cardio-thorac Surg. 2006;29:419-21.
11. Karmy-Jones R, Lee CA, Nicholls SC, Hoffer E. Management of aortobronchial fistula with an aortic stent-graft. Chest. 1999;116;255-7.

12. Yoo JH, Lee CT, Shim YS, Chung JW, Ahn H, Kim KW. Aortobronchial fistula presenting as recurrent hemoptysis and successfully treated with an endovascular stent graft. Respiration. 2001;68:537-9.

13. Kshettry VR, Kroshus TJ, Hertz MI, Hunter DW, Shumway SJ, Bolman RM 3rd. Early and late airway complications after lung transplantation: incidence and management. Ann Thorac Surg. 1997;63:1576-83.

14. Samano MN, Minamoto H, Junqueira JJM, Yamaçake KGR, Gomes HAP, Mariani AW, et al. Bronchial Complications Following Lung Transplantation. Transplantation Proceedings. 2009;41:921-6.

15. Wilson IC, Hasan A, Healey M, Villaquiran J, Corris PA, Forty J, et al Healing of the bronchus in pulmonary transplantation. Eur J Cardiothorac Surg. 1996;10:521-7.

16. Calhoon JH, Grover FL, Gibbons WJ, Bryan CL, Levine SM, Bailey SR, et al. Single lung transplantation. Alternative indications and technique. J Thorac Cardiovasc Surg. 1991;101:816-25.

17. Garfein ES, Ginsberg ME, Gorenstein L, McGregor CC, Schulman LL. Superiority of end-to-end versus telescoped bronchial anastomosis in single lung tansplantation for pulmonary emphysema. J Thorac Cardiovasc Surg. 2001;121:149-54.

18. Van De Wauwer C, Van Raemdonck D, Verleden GM, Dupont L, De Leyn $\mathrm{P}$, Coosemans. Risk factors for airway complications within the first year after lung transplantation. Eur J Cardio-thorac Surg.2007;31:703-10.

19. Nunley DR, Gal AA, Vega JD, Perlino C, Smith P, Lawrence EC. Saprophytic Fungal Infections and Complications Involving the Bronchial Anastomosis Following Human Lung Transplantation. Chest. 2002;122:1185-91.

20. Singh N, Husain S. Aspergillus Infections After Lung Transplantation: Clinical Differences in Type of Transplant and Implications for Management. J Heart Lung Transplant. 2003;22:258-66. 